\title{
Facile fabrication of hierarchical flower-like BSA/layered double hydroxide hybrids
}

\author{
Tao Zhang ${ }^{\mathrm{a}, \mathrm{b}}$, Yuming Zhou ${ }^{\mathrm{a} *}$, Shiwei Li ${ }^{\mathrm{a}}$, Jian Rong ${ }^{\mathrm{a}}$, Fengxian Qiu ${ }^{\mathrm{b} *}$ \\ a School of Chemistry and Chemical Engineering, Southeast University, Jiangsu \\ Optoelectronic Functional Materials and Engineering Laboratory, Nanjing 211189, \\ China \\ b Institute of Green Chemistry and Chemical Technology, Jiangsu University, \\ Zhenjiang 212013, China
}

Corresponding author:

Tel./fax: +86 2552090617

E-mail: fchem@163.com (Y. Zhou), fxqiu@126.com (F. Qiu) 


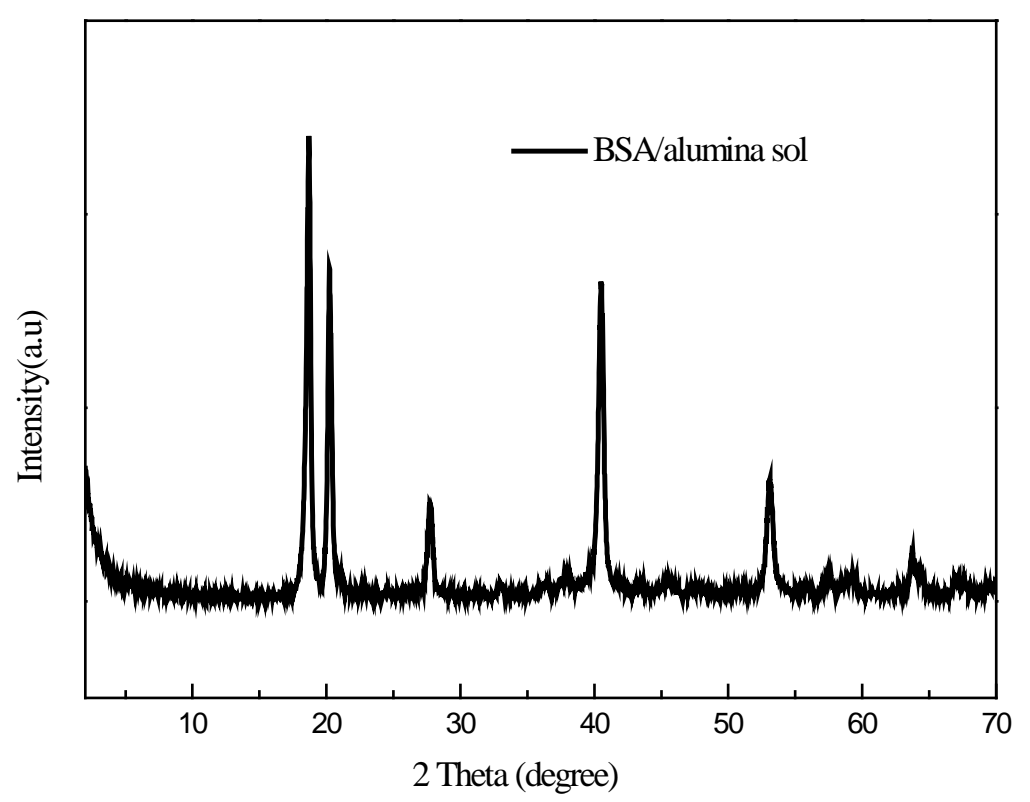

Fig.S1 XRD patterns of BSA/alumina sol

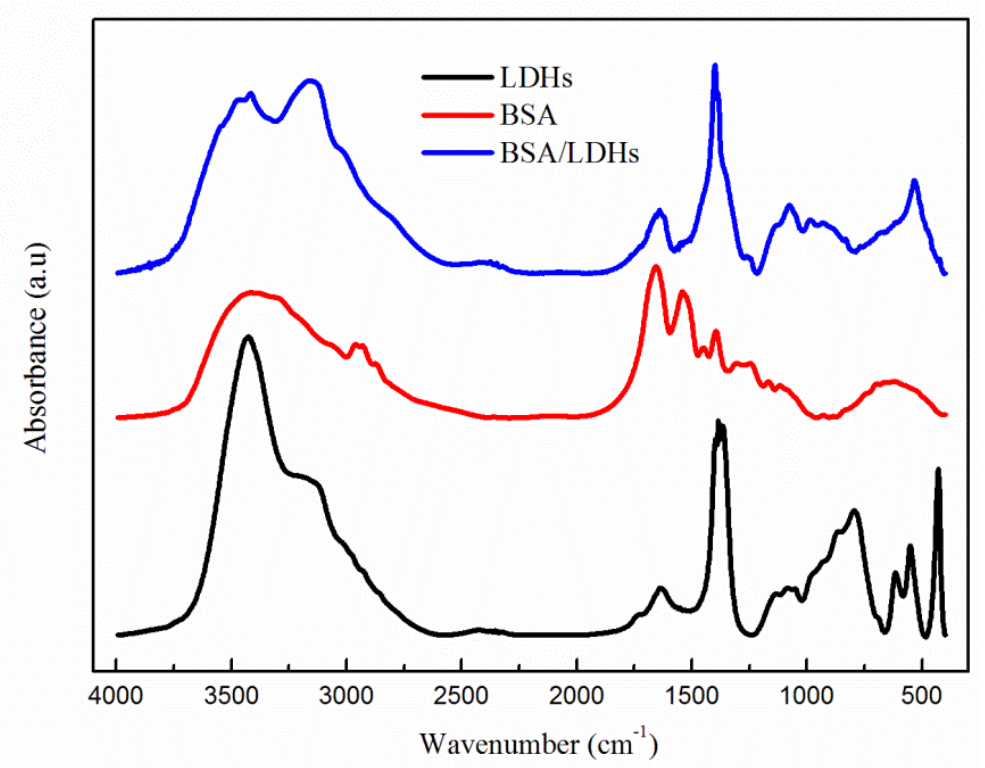

Fig.S2. FT-IR spectra of LDHs prepared by coprecipitation method, BSA and BSA/LDHs hybrids. 


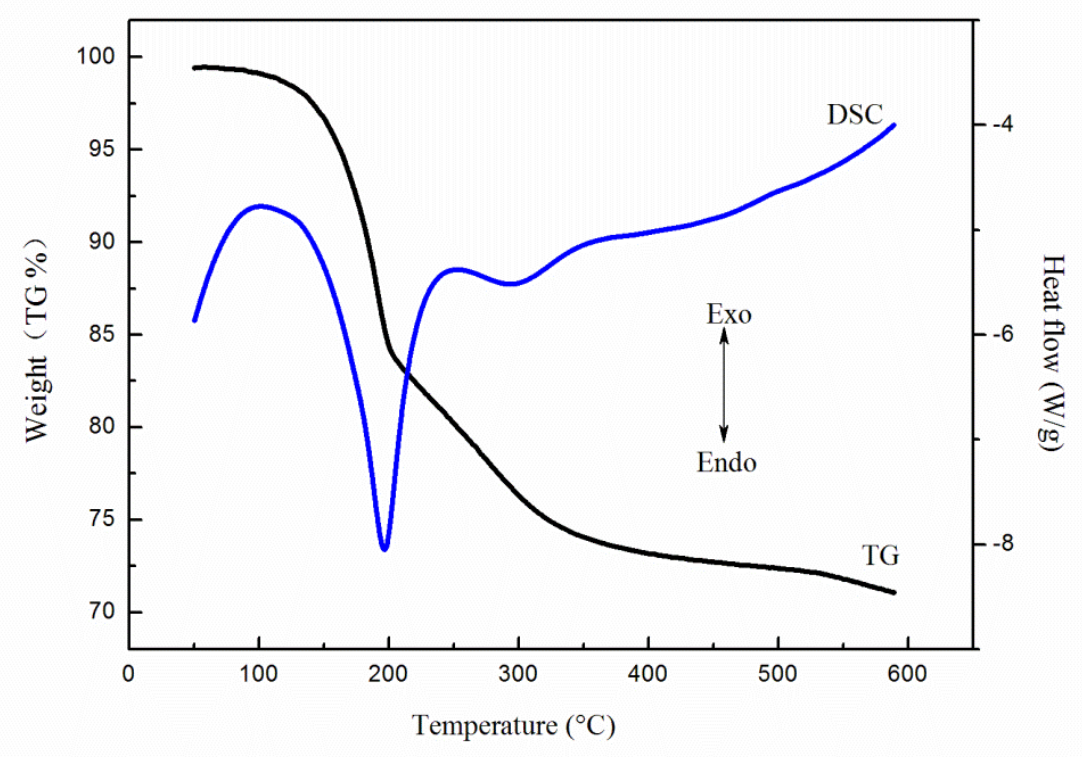

Fig. S3. TG-DSC curves of LDH

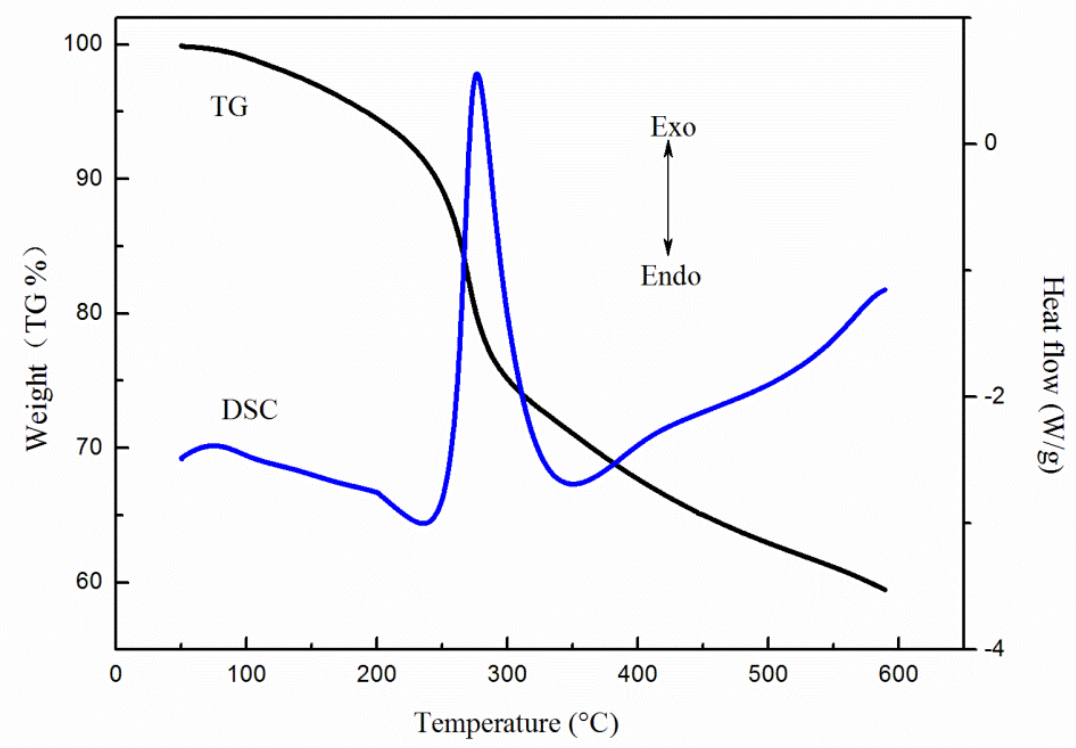

Fig. S4. TG-DSC curves of BSA/LDH hybrids. 